\title{
Interactions between Yeast Photolyase and Nucleotide Excision Repair Proteins in Saccharomyces cerevisiae and Escherichia coli
}

\author{
GWENDOLYN B. SANCAR* AND FRANCES W. SMITH \\ Department of Biochemistry, The University of North Carolina at Chapel Hill, \\ Chapel Hill, North Carolina 27599-7260
}

Received 25 April 1989/Accepted 19 July 1989

\begin{abstract}
The PHRI gene of Saccharomyces cerevisiae encodes a DNA photolyase that catalyzes the light-dependent repair of pyrimidine dimers. In the absence of photoreactivating light, this enzyme binds to pyrimidine dimers but is unable to repair them. We have assessed the effect of bound photolyase on the dark survival of yeast cells carrying mutations in genes that eliminate either nucleotide excision repair (RAD2) or mutagenic repair $(R A D 18)$. We found that a functional $P H R 1$ gene enhanced dark survival in a rad18 background but failed to do so in a rad2 or rad2 rad18 background and therefore conclude that photolyase stimulates specifically nucleotide excision repair of dimers in $S$. cerevisiae. This effect is similar to the effect of Escherichia coli photolyase on excision repair in the bacterium. However, despite the functional and structural similarities between yeast photolyase and the $E$. coli enzyme and complementation of the photoreactivation deficiency of $E$. coli phr mutants by PHR1, yeast photolyase failed to enhance excision repair in the bacterium. Instead, Phr1 was found to be a potent inhibitor of dark repair in recA strains but had no effect in uvrA strains. The results of in vitro experiments indicate that inhibition of nucleotide excision repair results from competition between yeast photolyase and $\mathrm{ABC}$ excision nuclease for binding at pyrimidine dimers. In addition, the $A$ and $B$ subunits of the excision nuclease, when allowed to bind to dimers before photolyase, suppressed photoreactivation by Phr1. We propose that enhancement of nucleotide excision repair by photolyases is a general phenomenon and that photolyase should be considered an accessory protein in this pathway.
\end{abstract}

The lethal, mutagenic, and carcinogenic effects of far-UV radiation are primarily attributable to the formation of pyrimidine dimers (cis-syn cyclobutane dipyrimidines) between adjacent bases on the same DNA strand. Given the prevalence of dimer-inducing wavelengths in the solar spectrum, it is not surprising that enzymatic pathways have evolved that either repair pyrimidine dimers or bypass the genotoxic effects of these lesions. The genetics and enzymology of these processes have been most extensively studied in Escherichia coli and Saccharomyces cerevisiae. Both organisms possess photoreactivation and nucleotide excision repair pathways that remove dimers from DNA (for recent reviews, see references 7 and 34); in addition, recombination, and perhaps transdimer synthesis, permits cells to temporarily tolerate a limited number of lesions $(9,11,17$, $25,30,48)$. Because pyrimidine dimers in DNA are potential substrates for several different repair pathways in the same cell, interactions between the components of these pathways must be considered in assessing the contribution of each pathway to repair and damage tolerance.

DNA photolyases repair pyrimidine dimers via a two-step process; dimers are bound by the enzyme, which subsequently absorbs a photon of near-UV light and uses this energy to cleave the cyclobutane ring linking the two pyrimidines (28). The fact that photolyases can bind dimers in the absence of the light necessary to catalyze photolysis immediately raises the question of whether bound photolyase enhances, inhibits, or has no effect on light-independent repair and tolerance processes. A number of in vivo studies have demonstrated that even in the absence of photoreactivating light, $E$. coli $p h r^{+}$strains are more resistant to UV-induced cell killing than are phr mutant strains and that this effect requires an active nucleotide excision repair

* Corresponding author. pathway $(12,13,50,51)$. Several years ago, we demonstrated that this characteristic is due to photolyase-mediated enhancement of dimer recognition by ABC excision nuclease (31), which catalyzes the first step in nucleotide excision repair, namely, incision of the damage-containing strand on each side of the lesion (34). Is this stimulation specific to the bacterial system, or does it reflect a more general phenomenon in which photolyases assist in the dark repair or tolerance of dimers? To answer this question, we now turn our attention to the interactions between photolyase and dark repair processes in yeast.

In $S$. cerevisiae, mutations in either of two loosely linked genes, $P H R I$ and $P H R 2$, inhibit photoreactivation of pyrimidine dimers $(20,27)$. $P H R I$ encodes a 66-kilodalton photolyase containing both flavin and folate chromophores $(34,35$, 38); although the function of $P H R 2$ is not known, it appears that this gene serves an ancillary function rather than eilcoding a second photolyase $(20,34)$. In addition to genes involved in photoreactivation, approximately 30 genetic loci have been identified which, when mutated, alter the ability of yeast cells to repair or tolerate pyrimidine dimers in the dark (7). In general, each locus has been assigned to one of three epistasis groups, each of which is thought to correspond to a different pathway for the repair or tolerance of UV-induced DNA damage $(7,9)$. Genes in the $R A D 3$ epistasis group are involved in nucleotide excision repair, whereas those in the $R A D 6$ and $R A D 52$ epistasis groups are involved in UV-induced mutagenesis and recombination, respectively. To assess the contribution of photolyase to the dark repair and tolerance of dimers, we have quantitated the survival, after UV irradiation and subsequent incubation in the dark, of strains carrying $\operatorname{rad} 2$ (RAD3 epistasis group) or rad18 (RAD6 epistasis group) mutations and either an active or an inactive $P H R I$ gene. In addition, the similarity of the Phrl photolyase to that of $E$. coli with respect to primary 
TABLE 1. E. coli strains used

\begin{tabular}{|c|c|c|}
\hline Strain & Genotype & Source, reference, or comments \\
\hline AB1157 & $\begin{array}{l}\text { thr-1 leuB6 proA2 hisG4 argE3 thi-1 ara-14 lacY1 galK2 } \\
\text { xyl-5 mtl-1 rpsL31 tsx33 } \lambda^{-} \text {supE44 }\end{array}$ & $\mathrm{CGSC}^{a}(4)$ \\
\hline AB2463 & recA13 AB1157 & $\mathrm{CGSC}^{a}(15)$ \\
\hline CSR06 & phr-1 uvrA6 AB1157 & $\operatorname{CGSC}^{a}(33)$ \\
\hline CSR603 & recAl phr-1 uvrA6 AB1157 & $\operatorname{CGSC}^{a}(32,33)$ \\
\hline MCL31 & $\begin{array}{l}\text { HfrP0201 } \Delta(\text { gpt-lac)5 relA1 rpsE2123 thi-1 supE44 TP3 } \\
\quad \Delta(\text { srl-recA } 306:: \operatorname{Tn} 10\end{array}$ & M. Lorence and C. S. Rupert (19) \\
\hline NK6033 & HfrP01 $\Delta($ gpt-lac $) 5$ nadA50::Tn10 relA1 spoT1 thi-1 $\lambda^{-}$ & N. Kleckner via CGSC ${ }^{a}$ \\
\hline UNC06 & nadA50::Tn10 phr-1 uvrA6 AB1157 & $\begin{array}{l}\text { G. Payne and A. Sancar; P1 transduction of nadA50::Tn10 } \\
\text { from NK6033 into CSR06 }\end{array}$ \\
\hline UNC1157 & nadA50 $\left(\operatorname{Tn} 10^{-}\right)$phr-1 AB1157 & $\begin{array}{l}\text { This work; P1 transduction of phr-l from UNC06 into } \\
\text { AB1157, followed by curing of Tn } 10\end{array}$ \\
\hline UNC2157 & $\Delta(\operatorname{srl}-\operatorname{rec} A) 306\left(\operatorname{Tn} 10^{-}\right)$nadA50 $\left(\operatorname{Tn} 10^{-}\right) p h r-1$ & $\begin{array}{l}\text { This work; P1 transduction of } \Delta(\text { srl-recA }) 306 \text { from MCL31 } \\
\text { into UNC1157, followed by curing of Tn } 10\end{array}$ \\
\hline UNC4000 & $\begin{array}{l}\text { gyrA96 recAl relAl endAl thi-l hsdR17 supE44 } \\
\left(\mathrm{F}^{\prime}\left[\operatorname{lacl}^{9} \mathrm{LS}^{\mathrm{p}} \text { proAB }{ }^{+}\right]\right)\end{array}$ & Previously reported as $\mathrm{DH} 1 / \mathrm{F}^{\prime} \operatorname{lacI^{q}} L 8(37)$ \\
\hline UNC4001 & phr-1 uvrA6 AB1157 ( $\mathrm{F}^{\prime}\left[\operatorname{lacI}^{\mathrm{q}} L 8\right.$ proAB $\left.\left.{ }^{+}\right]\right)$ & This work; plasmid transconjugant of UNC4000 $\times$CSR06 \\
\hline UNC4002 & $\operatorname{recA13} \mathrm{AB} 1157\left(\mathrm{~F}^{\prime}\left[\operatorname{lacl}^{9} L_{8}\right.\right.$ proAB $\left.\left.{ }^{+}\right]\right)$ & This work; plasmid transconjugant of UNC4000 $\times \mathrm{AB} 2463$ \\
\hline UNC4003 & 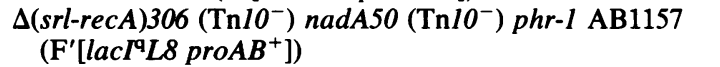 & This work; plasmid transconjugant of UNC4000 $\times$ UNC2157 \\
\hline UNC4004 & $\begin{array}{l}\Delta(\text { srl-recA }) 306\left(\mathrm{Tn} 10^{-}\right) \text {nadA50 }\left(\mathrm{Tn} 10^{-}\right) \text {phr-1 AB1157 } \\
\quad\left(\mathrm{pMS} 2\left[\mathrm{phr} r^{+}\right]\right)\end{array}$ & $\begin{array}{l}\text { This work; UNC2157 transformed with pMS } 2 \text { carrying the } \\
\text { E. coli phr gene }\end{array}$ \\
\hline UNC4005 & $\begin{array}{l}\Delta(\operatorname{srl}-r e c A) 306\left(\mathrm{Tn} 10^{-}\right) \operatorname{nadA50}\left(\mathrm{Tn} 10^{-}\right) \text {phr-1 AB1157 } \\
\quad\left(\mathrm{F}^{\prime}\left[\text { lacI }^{9} L 8 \text { proAB }\right.\right. \\
\end{array}$ & This work; UNC4003 transformant \\
\hline UNC4006 & 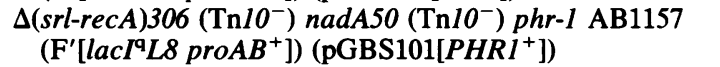 & $\begin{array}{l}\text { This work; UNC } 4003 \text { transformed with pGBS101 carrying } \\
\text { the } S \text {. cerevisiae PHRI gene }\end{array}$ \\
\hline UNC4007 & $\begin{array}{l}\Delta(\text { srl-recA }) 306\left(\mathrm{Tn} 10^{-}\right) \text {nadA50 }\left(\mathrm{Tn} 10^{-}\right) \text {phr-1 AB1157 } \\
\quad\left(\mathrm{F}^{\prime}\left[\text { lac } I^{9} L 8 \text { proAB }{ }^{+}\right]\right)(\mathrm{pCB} 9[\text { phrl] })\end{array}$ & $\begin{array}{l}\text { This work; UNC } 4003 \text { transformed with pCB9 carrying a } \\
\text { truncated } S \text {. cerevisiae PHRI gene }\end{array}$ \\
\hline UNC4008 & 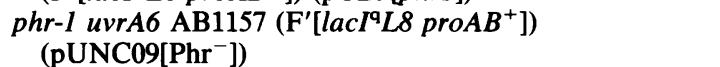 & This work; UNC4001 transformant \\
\hline UNC4009 & $\begin{array}{l}\text { phr-l uvrA6 AB1157 }\left(\mathrm{F}^{\prime}\left[\operatorname{lacl}^{\mathrm{q}} L 8 \text { proAB }{ }^{+}\right]\right) \\
\quad\left(\mathrm{pGBS} 101\left[\mathrm{PHR}^{+}\right]\right)\end{array}$ & $\begin{array}{l}\text { This work; UNC } 4001 \text { transformed with pGBS101 carrying } \\
\text { the } S \text {. cerevisiae PHRI gene }\end{array}$ \\
\hline
\end{tabular}

a Obtained from B. Bachmann, E. coli Genetic Stock Center (CGSC), Yale University, New Haven, Conn.

sequence $(35,39,52)$, chromophore content (34), and DNA binding (1) prompted us to ask whether the yeast enzyme can substitute for the bacterial photolyase in stimulating $E$. coli ABC excision nuclease. Our results indicate that stimulation of nucleotide excision repair by photolyases in the dark is likely to be a general phenomenon but that sufficient differences in substrate binding, protein-protein interactions, or both have accumulated during evolution to preclude stimulation of excision by photolyases from distantly related species.

\section{MATERIALS AND METHODS}

Plasmids. Constructions of all plasmids used in this study have been reported previously. Plasmid pGBS107 is a derivative of the yeast- $E$. coli shuttle vector pBM258 (Amp ${ }^{\mathrm{r}}$ CEN4 URA3 ARS1) in which the coding sequence of the $S$. cerevisiae PHRI gene has been fused to the GAL10 promoter and upstream regulatory sequences present on the plasmid, thereby rendering expression of $P H R I$ galactose inducible and glucose repressible (37). Plasmid pGBS101 carries the $P H R I$ coding sequences inserted 360 base pairs downstream from the tac promoter and ribosome-binding site in the $E$. coli plasmid pUNC09 (36); addition of lactose or isopropylthio- $\beta$-D-galactoside (IPTG) to cells carrying pGBS101 induces expression of the yeast $P H R I$ gene in $E$. coli. pCB9 is a derivative of pGBS101 in which the 509 base pairs between tac and the second ATG in the PHRI open reading frame have been deleted; induction of $\mathrm{pCB} 9$ leads to the synthesis of an inactive truncated form of yeast photolyase (37). Plasmid pMS2 is a derivative of pBR322 that carries the entire phr gene of $E$. coli (40).
Strains, constructions, and growth media. E. coli strains used in this study are listed in Table 1. Strains CH06, UNC1157, and UNC2157 were constructed by using standard transduction techniques for bacteriophage P1 (23). After confirmation of the desired genotype, the constructs were cured of transposon-encoded tetracycline resistance by growth on fusaric acid and chlortetracycline $(2,21)$. Transformations and matings were performed as described previously $(23,33)$. Cultures to be irradiated were grown in Luria broth supplemented with appropriate antibiotics (streptomycin, $50 \mu \mathrm{g} / \mathrm{ml}$; tetracycline, $20 \mu \mathrm{g} / \mathrm{ml}$ ).

The yeast strains used (Table 2) were constructed by using standard genetic techniques (42). Growth media (42) used in the course of the UV resistance studies were YPAD $(1 \%$ yeast extract, $2 \%$ peptone, $2 \%$ dextrose, $0.003 \%$ adenine hemisulfate), SC (synthetic complete medium), SC-ura (SC lacking uracil), and YPG (1\% yeast extract, $2 \%$ peptone, $3 \%$ glycerol). Transformations were performed as described by Hinnen et al. (14), selecting for uracil prototrophy conferred by pGBS107. In some cases, transformed strains were cured of pGBS107 by growing the strains for approximately 20 generations in YPAD, followed by plating of dilutions on YPAD and replica plating onto SC-ura to screen for loss of the plasmid-borne $U R A 3$ gene.

UV survival. Far-UV ( $254 \mathrm{~nm})$ light was supplied by a germicidal lamp (G8T5; General Electric Co., Schenectady, N.Y.), and all irradiations, subsequent manipulations, and growth were carried out under Sylvania F40 gold fluorescent lamps to prevent uncontrolled photoreactivation.

Overnight, stationary-phase cultures of $E$. coli strains without plasmids $\left(A_{600}=4.0\right)$ were washed twice in phos- 
TABLE 2. S. cerevisiae strains used

\begin{tabular}{|c|c|c|}
\hline Strain & Genotype & Source, reference, or comments ${ }^{a}$ \\
\hline $\mathrm{X} 12-6 \mathrm{~B}$ & a radl-1 ade2-1 & YGSC $^{b}$ \\
\hline JG-18 & a rad18-2 ade2 his5 lys1 leul & YGSC $^{b}$ \\
\hline DBY745 & $\alpha$ ade1-101 leu2-3,112 ura3-52 & David Botstein via Howard Fried \\
\hline GBS1 & $\alpha$ rad2 phrl adel leu2 & This laboratory; XS217-5B (37) $\times$ GBS58 \\
\hline GBS2 & a rad2 phrl adel gallo trpl & This laboratory (37) \\
\hline GBS46 & a phrl trpl ura3-52 & This work; X12-6B $\times$ DBY745 \\
\hline GBS55 & $\alpha$ phrl leu2-3,112 trpl ura3-52 & This work; GBS46 $\times$ DBY745 \\
\hline GBS57 & a rad18-2 phrl his5 leu2-3,112 lysl trpl ura3-52 & This work; GBS55 $\times$ JG-18 \\
\hline GBS58 & a radl8-2 his5 leul trpl ura3-52 & This work; GBS55 $\times$ JG-18 \\
\hline GBS88 & a rad2 phrl leu2-3,112 trp1 ura3-52(pGBS107[PHRI]) ${ }^{c}$ & $\begin{array}{l}\text { This laboratory; previously called GBS76 } \\
\text { [pGBS107] (37) }\end{array}$ \\
\hline GBS89 & a rad2 phrl leu2-3,112 trpl ura3-52 (pGBS107- $)^{d}$ & This laboratory (37) \\
\hline GBS90 & $\alpha$ rad18-2 phrl his5 leu2-3,112 lys1 trpl ura3-52 (pGBS107[PHRI]) & This work \\
\hline GBS91 & $\alpha$ rad18-2 phr1 his5 leu2-3,112 lys1 trp1 ura3-52 (pGBS107-) & This work \\
\hline GBS93 & $\alpha$ rad2 rad18-2 phrl ura3-52 trpl leul leu2 & This work; GBS1 1 GBS58 \\
\hline GBS94 & $\alpha$ rad2 rad18-2 phrl ura3-52 trpl leul leu2 (pGBS107[PHRI]) ${ }^{c}$ & This work \\
\hline GBS95 & $\alpha$ rad2 radl8-2 phrl ura3-52 trpl leul leu2 $\left(\mathrm{pGBS107}^{-}\right)^{d}$ & This work \\
\hline
\end{tabular}

${ }^{a}$ Where genetic crosses are indicated, the resultant strain is a haploid sporulation product.

${ }^{b}$ Obtained from the Yeast Genetic Stock Center (YGSC), University of California, Berkeley, Calif.

$c$ Ploidy is not necessarily the same as that of the original nontransformed strain.

${ }^{d} \mathrm{~A} \mathrm{Ura}^{-} \mathrm{Phr}^{-}$segregant of the parental plasmid-containing strain.

phate-buffered saline (PBS), resuspended in PBS to an $A_{600}$ of 0.3 , irradiated with stirring in $10-\mathrm{ml}$ samples in $100-\mathrm{ml}$ custard dishes, diluted in PBS, and plated on Luria broth agar. Surviving colonies were counted after 16 to $24 \mathrm{~h}$ of incubation at $37^{\circ} \mathrm{C}$. For survival of $E$. coli strains carrying tac plasmids, cells were grown to late log phase $\left(A_{600}=0.8\right)$, at which time IPTG was added to a final concentration of 2 mM. Two hours later, the cells were washed, irradiated, plated, and incubated as described above.

$S$. cerevisiae strains without galactose-inducible promoter plasmids were grown to stationary phase $(<10 \%$ budding cells, $A_{600}=16$ to 20), washed in PBS, diluted, and irradiated as described above. Postirradiation dilution in PBS was followed by plating on YPAD agar. Plates were incubated for 72 to $80 \mathrm{~h}$ at $30^{\circ} \mathrm{C}$ before surviving colonies were counted. Yeast strains harboring plasmid pGBS107 and control strains cured of the plasmid were cultured and irradiated as described previously (37). To induce transcription from the GAL10 promoter, galactose was added to $2 \%$ to mid-logphase cultures in YPG; 3 to $4 \mathrm{~h}$ later, the cells were washed, irradiated, and plated as described above. When flash photoreactivation was to be performed before dilution and plating, 5-ml samples from the irradiated mixture were transferred to $20-\mathrm{ml}$ glass test tubes before administration of photoreactivating light via the simultaneous discharge of two photographic flash units (Vivitar model 283).

Preparation of substrates for in vitro assays. ${ }^{3} \mathrm{H}$-labeled pBR322 DNA was prepared by amplification of the plasmid in the presence of $\left[{ }^{3} \mathrm{H}\right]$ thymidine, followed by purification of plasmid DNA by $\mathrm{CsCl}$-ethidium bromide density gradient centrifugation (41). Purified plasmid DNA $(20 \mu \mathrm{g} / \mathrm{ml})$ was irradiated with 254-nm light to produce the desired number of pyrimidine dimers per molecule as quantitated by the transformation assay (41). Plasmid DNA containing psoralen monoadducts was obtained by incubating unlabeled pBR322 DNA with $\left[{ }^{3} \mathrm{H}\right] 4^{\prime}$-hydroxymethyl-4,5',8-trimethylpsoralen (HMT; $12 \mathrm{Ci} / \mathrm{mmol}$; HRI Associates, Emoryville, Calif.) as follows: a mixture consisting of HMT $(25 \mathrm{ng} / \mathrm{ml})$ and plasmid DNA (57 nM) in TEN buffer (10 mM Tris [pH 7.4], $10 \mathrm{mM}$ $\mathrm{NaCl}, 1 \mathrm{mM}$ disodium EDTA) was incubated on ice and under yellow safe lights for $\mathbf{3 0}$ min. Covalent adducts were formed by irradiating the HMT-DNA solution on ice at a fluence rate of $40 \mathrm{~J} / \mathrm{m}^{2}$ per s (delivered by a B-100A BlackRay lamp; UV Products, Inc., San Gabriel, Calif.) for 15 min, after which the DNA was precipitated twice with $0.3 \mathrm{M}$ sodium acetate and 2.5 volumes of $95 \%$ ethanol and then dissolved in TEN buffer and dialyzed against 10,000 volumes of the same buffer. The final HMT-DNA preparation had a specific activity of $58,800 \mathrm{dpm} / \mu \mathrm{g}$.

In vitro assay for incision by $\mathrm{ABC}$ excision nuclease in the presence or absence of yeast photolyase. The UvrA, UvrB, and UvrC subunits of $E$. coli ABC excision nuclease and $S$. cerevisiae $\mathrm{Phr} 1$ photolyase were purified as previously described $(38,44)$. Assays to monitor incision of adducted pBR322 DNA by ABC excision nuclease were performed in $A B C$ assay buffer (50 mM Tris [pH 7.5], $50 \mathrm{mM} \mathrm{KCl}, 10 \mathrm{mM}$ $\mathrm{MgCl}_{2}, 10 \mathrm{mM}$ dithiothreitol, $2 \mathrm{mM}$ ATP, $1 \mathrm{mg}$ of bovine serum albumin per $\mathrm{ml}$ ) containing as substrate either UVirradiated ${ }^{3} \mathrm{H}$-labeled pBR322 DNA (2.6 nM DNA, 3 pyrimidine dimers per plasmid molecule) or $\left[{ }^{3} \mathrm{H}\right] \mathrm{HMT}$-treated plasmid DNA (3.1 nM DNA, 6.2 adducts per plasmid molecule). The reaction mixture was assembled on ice; then yeast photolyase ( $320 \mathrm{nM})$ or a comparable volume of dilution buffer was added, and the mixture was incubated at room temperature for $10 \mathrm{~min}$ to allow photolyase-pyrimidine dimer complex formation. A mixture of UvrA, UvrB, and UvrC proteins $(70,300$, and $31 \mathrm{nM}$, respectively) was then added, the mixtures were transferred to a $37^{\circ} \mathrm{C}$ heat block, and at various times $35-\mu$ l samples were added to $15 \mu$ l of stoploading solution ( $83 \mathrm{mM}$ disodium EDTA, $10 \mathrm{mM}$ Tris [pH 7.4], $1 \%$ sodium dodecyl sulfate, $5 \%$ glycerol, $0.01 \%$ bromophenol blue). The samples were then heated at $70^{\circ} \mathrm{C}$ for 5 min and loaded onto vertical $0.8 \%$ agarose gels in $\mathrm{E}$ buffer (40 mM Tris [pH 8.0], $20 \mathrm{mM}$ sodium acetate, $18 \mathrm{mM} \mathrm{NaCl}$, $2 \mathrm{mM}$ disodium EDTA). The separated covalently closed circular and open circular DNA bands were visualized by staining with ethidium bromide $(2 \mu \mathrm{g} / \mathrm{ml})$, excised from the gel, and dissolved in $0.5 \mathrm{ml}$ of $1 \mathrm{~N} \mathrm{HCl}$ at $90^{\circ} \mathrm{C}$ for $30 \mathrm{~min} ; 5$ ml of Scintiverse I (Fisher Chemicals) was added, and the radioactivity in each band was quantitated by using a Rackbeta 1214 liquid scintillation counter (LKB Instruments, Inc., Rockville, Md.). The average number of incisions per plasmid molecule $(I)$ at each time point was calculated from the relationship $\mathrm{dpm}_{\mathrm{ccc}} / \mathrm{dpm}_{\text {total }}=e^{-I}$, where $\mathrm{dpm}_{\mathrm{ccc}}$ l 
$\mathrm{dpm}_{\text {total }}$ is the fraction of total disintegrations per minute remaining in covalently closed circular DNA and therefore not incised by the excision nuclease. These values were corrected for the amount of open circular DNA present at zero time ( 25 and $5 \%$ of the total for UV-irradiated DNA and HMT-modified DNA, respectively).

Assay for photoreactivation in vitro in the presence or absence of UvrA and UvrB proteins. Mixtures containing UvrA and UvrB proteins at various concentrations, or an equal volume of dilution buffer, were added to UV-irradiated DNA (4.6 nM plasmid containing 2.2 pyrimidine dimers per molecule) in $A B C$ assay buffer and incubated at room temperature for $10 \mathrm{~min}$, after which photolyase was added to a final concentration of $2.7 \mathrm{nM}$. Two minutes later, the $300-\mu l$ reaction mixtures were transferred to individual compartments of 24-well microdilution dishes (Falcon; Becton Dickinson Labware, Oxnard, Calif.), and photoreactivation was begun by using a fluence of $4 \mathrm{~J} / \mathrm{m}^{2}$ of $365-\mathrm{nm}$ light per $\mathrm{m}^{2}$ per s supplied by a Sylvania Black Light bulb. At appropriate times, $10-\mu$ l samples were removed, added to $25 \mu$ l of 25 $\mathrm{mM}$ disodium EDTA, and stored in the dark. Portions of 10 $\mu l$ from these samples were used to transform the repairdeficient $E$. coli CSR603 to tetracycline resistance (31). The average number of dimers per molecule $(D)$ at each time point was determined from the relationship $S_{t} / S_{0}=e^{-D}$, where $S_{0}$ is the number of transformants obtained by using nonirradiated DNA of the same concentration and $S_{t}$ is the number of transformants after $t$ minutes of photoreactivation.

\section{RESULTS}

The PHRI gene enhances dark repair in $S$. cerevisiae. Comparison of UV survival curves of different yeast strains is frequently complicated by (unknown) differences in genetic background. To avoid such background effects in determining whether the $S$. cerevisiae $P H R I$ gene has an effect on dark-repair processes, we exploited the availability of plasmid pGBS107, which carries the $P H R 1$ gene fused to the galactose-inducible $G A L 10$ promoter (37). Our strategy was to transform dark-repair- and photoreactivation-deficient strains with pGBS107 and to compare the UV survivals of the resultant $\mathrm{PHR}^{+}$transformants with the survivals of $\mathrm{PHR}^{-}$segregants that had lost the plasmid. This strategy has the advantage that each strain is compared with a partner of the same ploidy that is completely isogenic except for the presence or absence of plasmid-borne genes. The complete genotypes of these strains are given in Table 2.

Figure 1A compares the dark survival, after galactose induction and 254-nm irradiation, of log-phase cultures of the rad18 pair GBS90 and GBS91. The presence of pGBS107 (GBS90) enhanced dark survival approximately 10-fold. In contrast, pGBS107 had no demonstrable effect on the dark survival of the rad2 pair GBS88 and GBS89 (Fig. 1B). The absence of survival enhancement was not due to failure of GBS88 to synthesize the $P H R I$ photolyase, as photoreactivation of UV-induced lethality was clearly demonstrable (Fig. 1B); rather, the ability of pGBS107 to stimulate dark survival was abolished either by inactivation of $R A D 2$ or by the presence of a wild-type $R A D 18$ gene. To discriminate between these possibilities, we compared the dark survivals of the rad2 rad18 pair GBS94 and GBS95. pGBS107 not only failed to enhance dark repair in GBS94 but actually inhibited repair (Fig. 1C). Although the mechanism of inhibition is not known, the finding that pGBS107 did not enhance survival in either a rad2 or rad2 radl8 background indicates that an active $R A D 2$ gene, or more likely an active nucleotide excision repair pathway, is required for stimulation of dark repair by pGBS107.

Logarithmically growing wild-type yeast strains contain 75 to 150 molecules of photolyase per cell and approximately twice this amount during stationary phase $(8,53)$. In contrast, galactose induction of log-phase cells carrying pGBS107 results in the synthesis of at least 1,800 to 2,400 molecules of photolyase per cell (37), and therefore it could be argued that the enhancement of dark survival observed in GBS90 is not physiologically significant in cells containing normal amounts of photolyase. To examine this question, we determined the dark survivals of strains GBS57 (rad18 phrl) and GBS58 (radl8 PHRl) in stationary phase; since neither strain contains pGBS107, any effect on dark repair is likely attributable to expression of the single chromosomal copy of $P H R 1$. Dark survival was significantly increased for strain GBS58 (Fig. 1D); although to a less dramatic extent, we have also observed enhancement of dark repair in log-phase GBS58 (data not shown). These results, in conjunction with the results obtained with the plasmid-containing strains, indicate that it is the $P H R I$ gene that is responsible for the stimulation of dark repair and that stimulation can be observed with normal levels of photolyase.

Yeast $P H R 1$ photolyase inhibits nucleotide excision repair in E. coli. Yamamoto et al. $(50,51)$ have reported that increased expression of $E$. coli photolyase, by virtue of either a purA mutation or the presence of a multicopy plasmid carrying $p h r$, increases the dark survival of $E$. coli recA $u v r^{+}$ mutants. Using a newly constructed $r e c A$ phr-l derivative of AB1157 called UNC2157 (Table 1), we have confirmed these observations (Fig. 2A). In addition, comparison of the survival of UNC2157 with that of AB2463 (a recA phr ${ }^{+}$derivative of $\mathrm{AB} 1157$ ) demonstrates that significant stimulation of dark repair occurs in stationary-phase $E$. coli with normal levels of photolyase.

The amino acid sequences of $E$. coli and $S$. cerevisiae photolyases are $37 \%$ identical, although certain regions of the proteins, including the carboxy-terminal 150 amino acids, exhibit greater than $50 \%$ identity $(35,52)$. In addition, both enzymes contain as chromophores reduced flavin adenine dinucleotide and 5,10-methenyltetrahydrofolate (34, 38 ), and the yeast $P H R I$ gene complements the photoreactivation deficiency in $E$. coli strains carrying $p h r$ mutations (36). These similarities strongly suggested that the genes encoding the yeast and $E$. coli photolyases evolved from a common ancestral gene and led us to ask whether the $S$. cerevisiae photolyase could also stimulate dark repair in a recA phrl E. coli strain. Plasmid pGBS101, which contains the entire yeast $P H R I$ gene fused to the strong inducible $t a c$ promoter, was used to transform $E$. coli UNC4003 (recA $p h r-1)$, and the dark survival of the resulting strain, UNC4006, was compared with those of the parental strain, of UNC4005 (UNC4003 transformed with the parental tac plasmid pUNC09), and of UNC4007 (UNC4003 transformed with pCB9, which carries a truncated $P H R I$ gene encoding an inactive photolyase [37]). To our surprise, we found that expression of yeast photolyase decreased the dark survival of UNC4006 compared with that of the control strains (Fig. 2B). Sensitization to UV must be due specifically to the presence of yeast photolyase and not simply to overproduction of any protein, as (1) induction of pGBS101 leads to the synthesis of only about 10 molecules of active yeast enzyme per cell (36), compared with the several thousand molecules per cell of $\beta$-lactamase produced when pUNC09 is induced (see, for example, reference 40), and (2) synthesis of the 

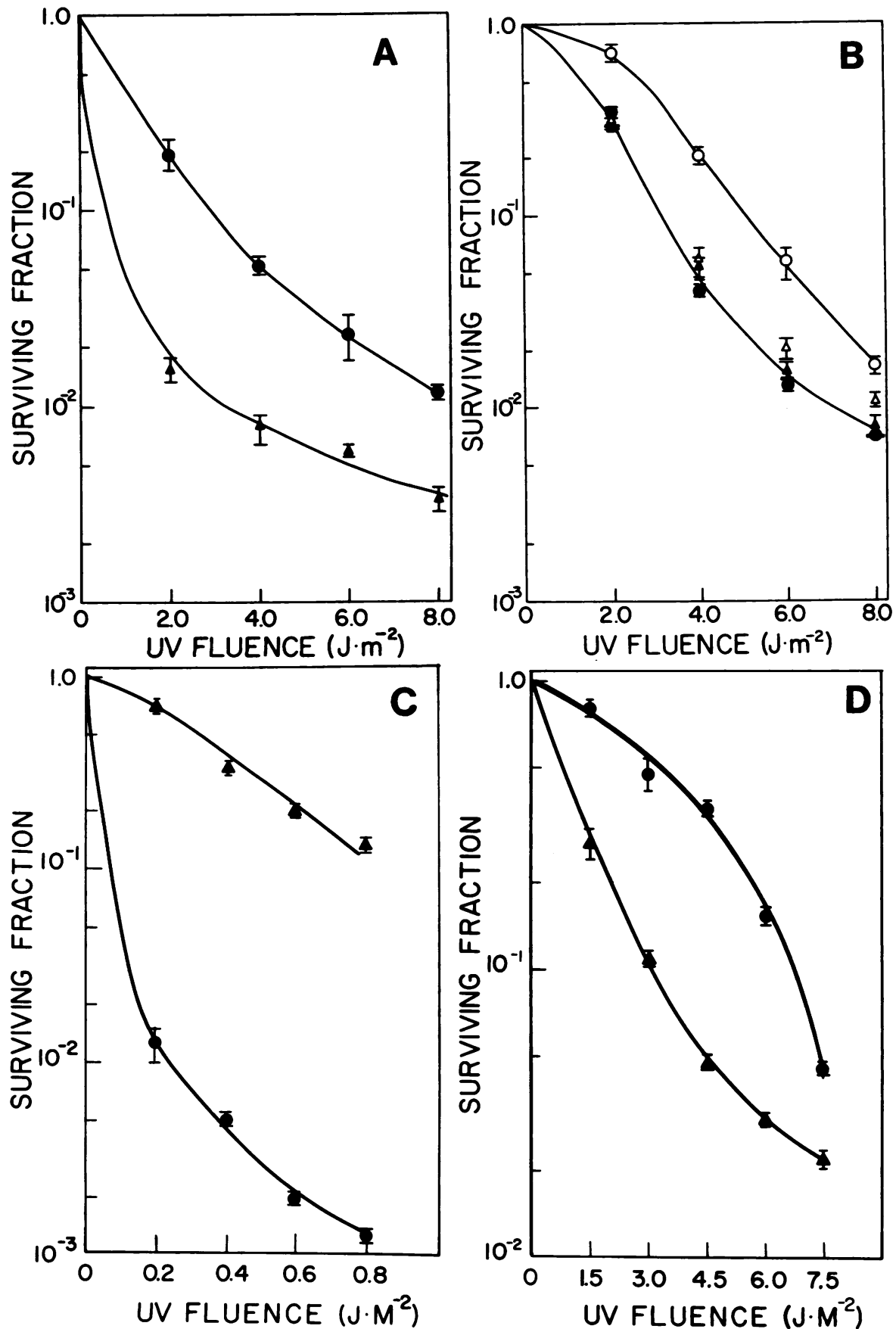

FIG. 1. Effect of an active $P H R I$ gene on the survival, after 254-nm irradiation, of $S$. cerevisiae strains carrying either radl8 or rad2 mutations. Error bars indicate the standard deviations of values obtained in two independent experiments performed as described in Materials and Methods. (A) Survival of cells from log-phase cultures of GBS90 (O; phrl radl8 pGBS107[PHRI]) and GBS91 (A; phrl rad18). (B) Survival of cells from log-phase cultures of GBS88 (๑; $\bigcirc$; phrl rad2 pGBS107[PHR1]) and GBS $89(\Delta, \triangle$; phrl rad2) either without $(\Theta, \Delta)$ or with $(O, \Delta)$ subsequent photoreactivation. (C) Survival of cells from log-phase cultures of GBS94 (O; phrl rad2 rad18 pGBS107[PHRI])

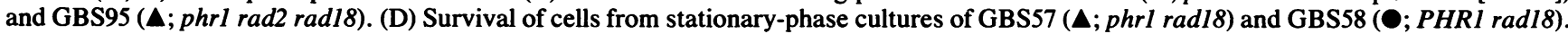

inactive yeast photolyase encoded by pCB9 does not sensitize the cells to 254 -nm radiation. The 10 - to 15 -fold reduction in survival afforded by the presence of active yeast photolyase at fluences of greater than $0.15 \mathrm{~J} / \mathrm{m}^{2}$ is quite striking considering the small amount of enzyme synthesized. The difference between the dose required to reduce survival to $0.1 \%$ for UNC4005 versus UNC4006 was approximately $0.15 \mathrm{~J} / \mathrm{m}^{2}$, corresponding to approximately nine fewer pyrimidine dimers repaired per cell in UNC4006 $(0.1$
$\mathrm{J} / \mathrm{m}^{2}$ of 254-nm radiation induces formation of six pyrimidine dimers per $E$. coli genome [29]). Since only about 10 yeast photolyase molecules were present per UNC4006 cell, this finding suggests that binding of the yeast enzyme to a pyrimidine dimer completely blocks repair via the only functional dark-repair pathway in these cells, namely, nucleotide excision repair.

To determine whether dark-repair functions dependent on the presence of an active $\operatorname{rec} A$ gene are also affected by 

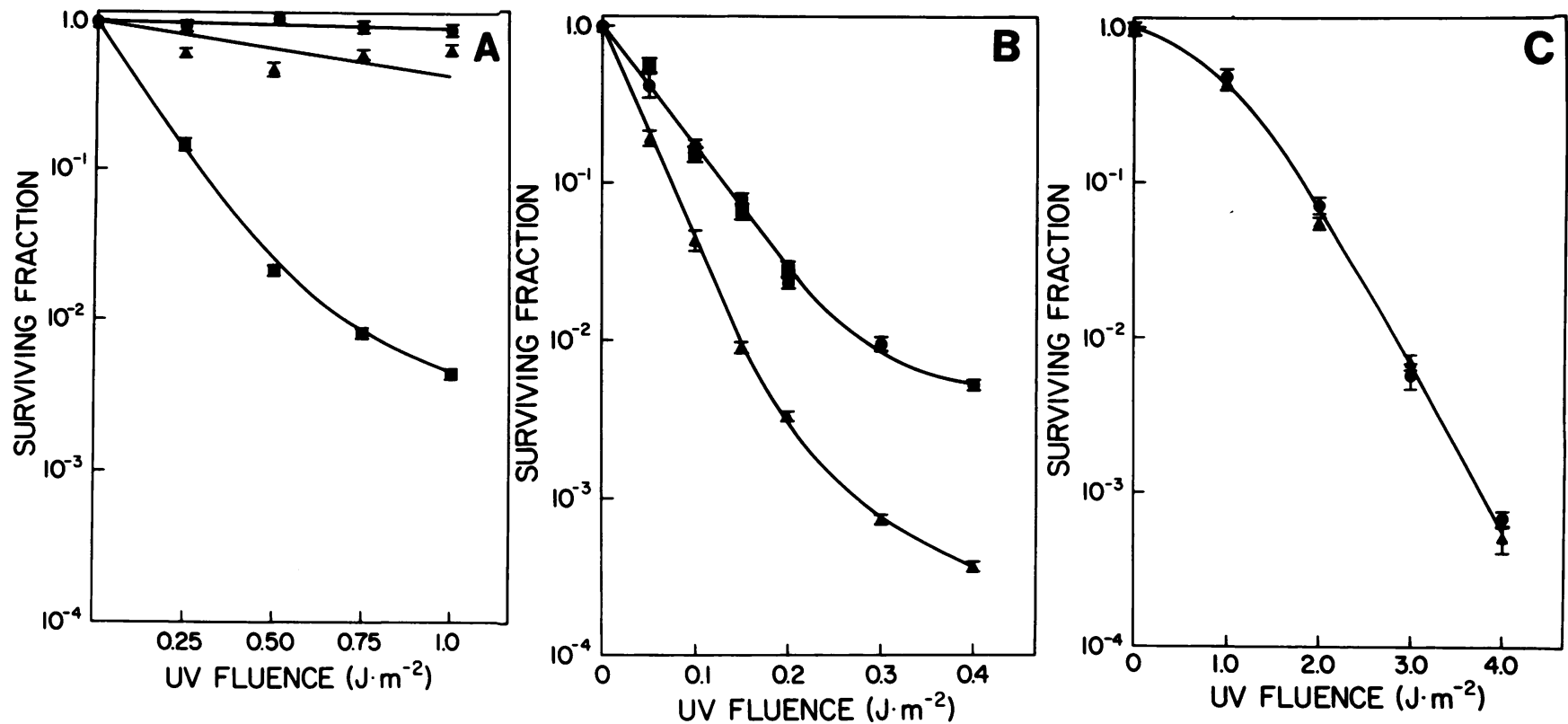

FIG. 2. Survival, after 254-nm irradiation, of various $E$. coli strains carrying mutations in either the recA or $u v r A$ gene and with or without active $E$. coli or yeast photolyase genes. Error bars indicate the standard deviations of two independent experiments. (A) Survival of stationary-phase $E$. coli UNC2157 (ם; recA phr), AB2463 (A; recA), and UNC4004 (O; recA phr-1 pMS2[phr $\left.\left.r^{+}\right]\right)$. (B) Survivals of log-phase strains UNC4005 (ם; recA phr-1 pUNC09), UNC4006 (A; recA phr-1 pGBS101[PHRl]), and UNC4007 (O; recA phr-1 pCB9[phrl]). (C)

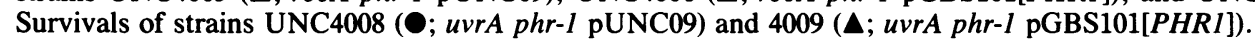

expression of yeast photolyase in $E$. coli, we examined the dark survivals of strains UNC4008 and UNC4009, which are derivatives of $\mathrm{AB} 1157$ carrying mutations in $u v r A$ and phr (Table 1). The survival of UNC4009 was unaffected by induction of PHRI on pGBS101 (Fig. 2C). Since we have previously shown that the dark survival of pGBS101-containing derivatives of CSR603 ( $p h r u v r A$ recA) is also unaffected under these conditions (36), we conclude that inhibition of dark repair by yeast photolyase in $E$. coli, like stimulation of dark repair by $E$. coli photolyase, requires an active nucleotide excision repair pathway but not active recA-mediated repair.

Interactions between yeast photolyase and $E$. coli $\mathrm{ABC}$ excision nuclease in vitro. In $E$. coli, the first step in nucleotide excision repair, incision of the damage-containing strand, requires UvrA, UvrB, and UvrC proteins acting in a multisubunit complex called ABC excision nuclease (34). We have previously demonstrated that $E$. coli photolyase stimulates incision by $\mathrm{ABC}$ excision nuclease at specific pyrimidine dimers $(24,31)$, thereby providing a biochemical explanation for the in vivo observation that $u v r^{+} \mathrm{phr}^{+}$ strains are more resistant to UV-induced cell killing in the dark than are $u v r^{+} p h r$ strains. Similar studies are not yet possible with the components of the yeast nucleotide excision repair pathway, since the specific proteins responsible for damage recognition and incision have not been identified. However, it is possible to explore the mechanism of inhibition of $E$. coli nucleotide excision repair by yeast photolyase by using entirely defined components in vitro. Such studies may also provide insight into the permissible dispositions of the yeast excision enzymes around pyrimidine dimers. Shown in Fig. 3 are the results of experiments comparing the rate of incision of UV-irradiated or HMT-adducted pBR322 DNA by $A B C$ excision nuclease with or without prior incubation with concentrations of yeast photolyase sufficient to bind $>90 \%$ of pyrimidine dimers. Incision of the plasmid
DNA is indicated by the conversion of radiolabeled covalently closed circular supercoiled DNA to relaxed circular DNA. As can be seen, yeast photolyase inhibited incision of UV-irradiated DNA but had no effect on incision of HMTadducted DNA. Quantitative analysis indicated that the yeast enzyme decreased both the rate and the final extent of incision of UV-irradiated DNA by a factor of approximately 2.5 (Fig. 4). The failure of photolyase to inhibit incision of HMT-modified DNA is consistent with the specificity of the enzyme in vivo (34) and demonstrates that inhibition is specific for lesions that are bound by photolyase. Thus, it is the interaction of photolyase with one or more components of the excision nuclease at the site of the pyrimidine dimer, rather than nonspecific interaction between the proteins in solution, that inhibits the excision nuclease.

$\mathrm{ABC}$ excision nuclease makes concerted incisions at the eighth phosphodiester bond $5^{\prime}$ and the fourth or fifth phosphodiester bond 3 ' to pyrimidine dimers and in the damaged strand (34). Although the incision assay described above will not discriminate between concerted cuts and cuts made at only one of the two normal incision sites, the results shown in Fig. 4 indicate that the excision nuclease is unable to incise on either side of a dimer at at least $60 \%$ of the lesions and therefore that a large proportion of lesions are inaccessible to one or more components of the excision nuclease when photolyase is bound.

Studies from several laboratories indicate that the A and B subunits of the excision nuclease are responsible for substrate recognition and bind to pyrimidine dimers and other UV-induced lesions in the absence of the $C$ subunit. Subsequent addition of the $\mathrm{C}$ subunit results in the dual incisions characteristic of the excision reaction (34). To further define the interactions involved in the inhibition of the incision reaction, we examined the effect of prior binding of the $A$ and $B$ subunits on photoreactivation by yeast photolyase in vitro. Incubation of $U V$-irradiated pBR322 with the A and B 


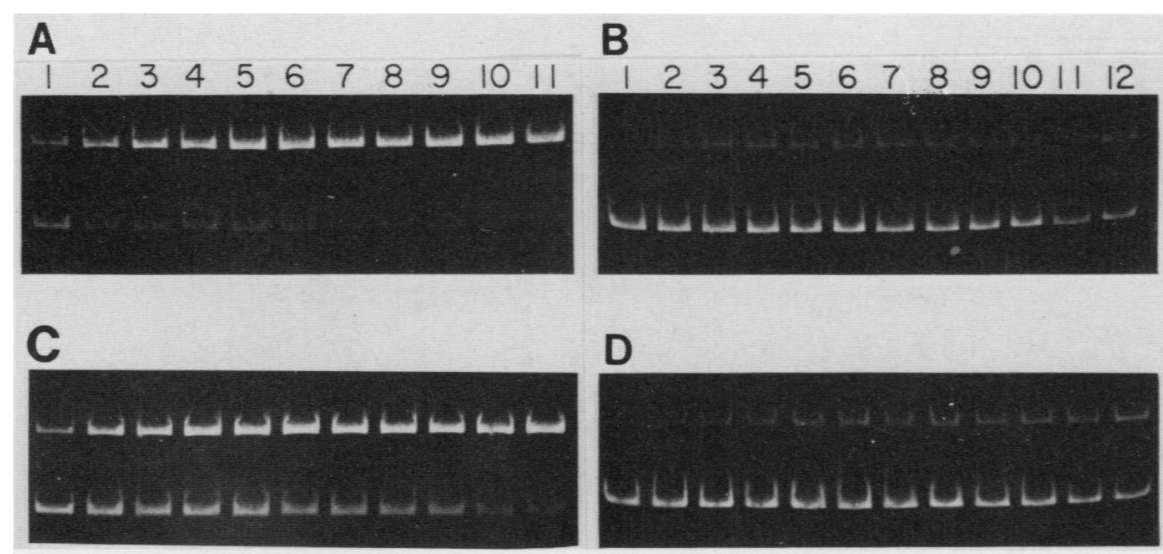

FIG. 3. Incision of UV-irradiated (A and C) or psoralen-adducted (B and D) DNA in vitro by $E$. coli $A B C$ excision nuclease in the presence $(\mathrm{C}$ and $\mathrm{D})$ or absence (A and B) of yeast photolyase. ${ }^{3} \mathrm{H}$-labeled pBR322 DNA containing either pyrimidine dimers or $\left[{ }^{3} \mathrm{H}\right] \mathrm{HMT}$ adducts was incubated with $\mathrm{ABC}$ excision nuclease with or without prior incubation with yeast photolyase, and samples were taken at various times during the course of the reaction as described in Materials and Methods. Shown are photographs of ethidium bromide-stained agarose gels in which nonincised covalently closed circular DNA (lower band in each panel) has been separated from incised open circular DNA. Lanes 1 to 11 on panels $A$ and $C$ contain samples taken, respectively, at $0,2,4,6,8,10,15,20,30,45$, and 60 min after initiation of the incision reaction; lanes 1 to 12 in panels $B$ and $D$ contain samples taken at $0,1,2,3,4,5,6,7,9,10,15$, and 60 min after initiation of the reaction. The decreased incision of HMT-modified DNA compared with UV-irradiated DNA in the absence of photolyase reflects the instability of the UvrC subunit and the fact that the assays using the two DNAs were performed several days apart; assays comparing incision on the same substrate were always performed simultaneously.

subunits of the nuclease before addition of photolyase inhibited the rate of dimer repair under conditions of limiting photolyase, and the degree of inhibition was proportional to the concentrations of the subunits (Fig. 5). The similarity in the rates of photoreactivation early in the reaction suggested that a fraction of dimers were not bound by the $A$ and $B$ subunits and that repair of these dimers by photolyase was unaffected. Taken together with the data presented above, these results indicate that at pyrimidine dimers, formation of A-DNA or AB-DNA complexes and binding by yeast photolyase are mutually exclusive events.

\section{DISCUSSION}

The light-dependent repair of pyrimidine dimers has long been the sole known function of DNA photolyases. Only recently has evidence been obtained that in $E$. coli, photolyase also plays a role in the dark repair of dimers; both in vivo and in vitro studies indicate that this role is stimulation of nucleotide excision repair via interaction between photolyase and $A B C$ excision nuclease $(12,13,24,31,50,51)$. In this report, we have presented evidence that photolyase performs a similar function in yeast cells. $\mathrm{Phr}^{+}$strains are more resistant than $\mathrm{Phr}^{-}$strains to UV killing, and this $P H R I$-dependent resistance is abolished by a mutation in the $R A D 2$ gene, the product of which is required for the incision step of nucleotide excision repair in yeast cells $(7,49)$, but is unaffected by a mutation in the RAD18 gene, which is involved in mutagenic repair $(18,25)$. Although we have not assessed the effect of photolyase on dark repair in $\mathrm{Rad}^{+}$ strains, others have found that $\mathrm{Rad}^{+} \mathrm{Phr}^{+}$and $\mathrm{Rad}^{+} \mathrm{Phr}^{-}$ strains survive $254-\mathrm{nm}$ radiation about equally well in the absence of photoreactivating light $(10,26)$; this finding presumably reflects both the efficiency of the nucleotide excision repair and dimer tolerance pathways in $S$. cerevisiae and the induction of substantial numbers of lethal nondimer lesions at the high fluences required to saturate these pathways.

Does the similarity in the phenotypes resulting from interactions between photolyase and nucleotide excision repair in yeast cells and $E$. coli reflect a common mechanism? The amino acid sequences of $E$. coli photolyase and the Phr1 photolyase from $S$. cerevisiae exhibit $37 \%$ identity overall and greater than $50 \%$ identity over the carboxyterminal 144 amino acids $(35,52)$. In addition, the proteins contain the same two intrinsic chromophores $(34,38)$, and as is demonstrated in the accompanying paper, the contacts made on DNA by these two enzymes are quite similar (1). Thus, all indications are that the structures of yeast and $E$. coli photolyases are likewise similar. Although the precise mechanism of nucleotide excision repair in yeast cells is not known, several lines of evidence suggest that it resembles that utilized in $E$. coli. In both organisms, pyrimidine dimers and a variety of bulky nondimer lesions are excised from DNA via this pathway $(7,15,34)$. Excision is accompanied by the release of additional nucleotides from the DNA, although it is not clear whether in yeast cells this reflects concerted phosphodiester bond cleavage both $5^{\prime}$ and $3^{\prime}$ to the lesion as it does in $E$. coli $(6,34,45)$. Incision requires multiple gene products, and mutations in any of several genes abolish incision at all lesions normally repaired via this pathway $(7,34,49)$. The results of photolyase footprinting studies reported in the accompanying paper (1) demonstrate that at least two to three phosphodiester bonds on each side of the dimer are inaccessible to other DNA-binding proteins when yeast photolyase is bound; that photolyase does not inhibit nucleotide excision repair in yeast cells strongly suggests that the initial incision(s) must be at least this distance from the dimer. Taken together with the observation that the Phr1 photolyase stimulates specifically nucleotide excision repair of pyrimidine dimers, the available evidence strongly suggests that stimulation is a consequence of interactions occurring in a ternary complex composed of the pyrimidine dimer and surrounding nucleotides, photolyase, and a multisubunit complex that incises the damaged strand at some distance from the pyrimidine dimer. That this phenomenon is not limited to bacteria and unicellular eucaryotes is suggested by the report that a photorepairdeficient mutant in Drosophila melanogaster is also partially 

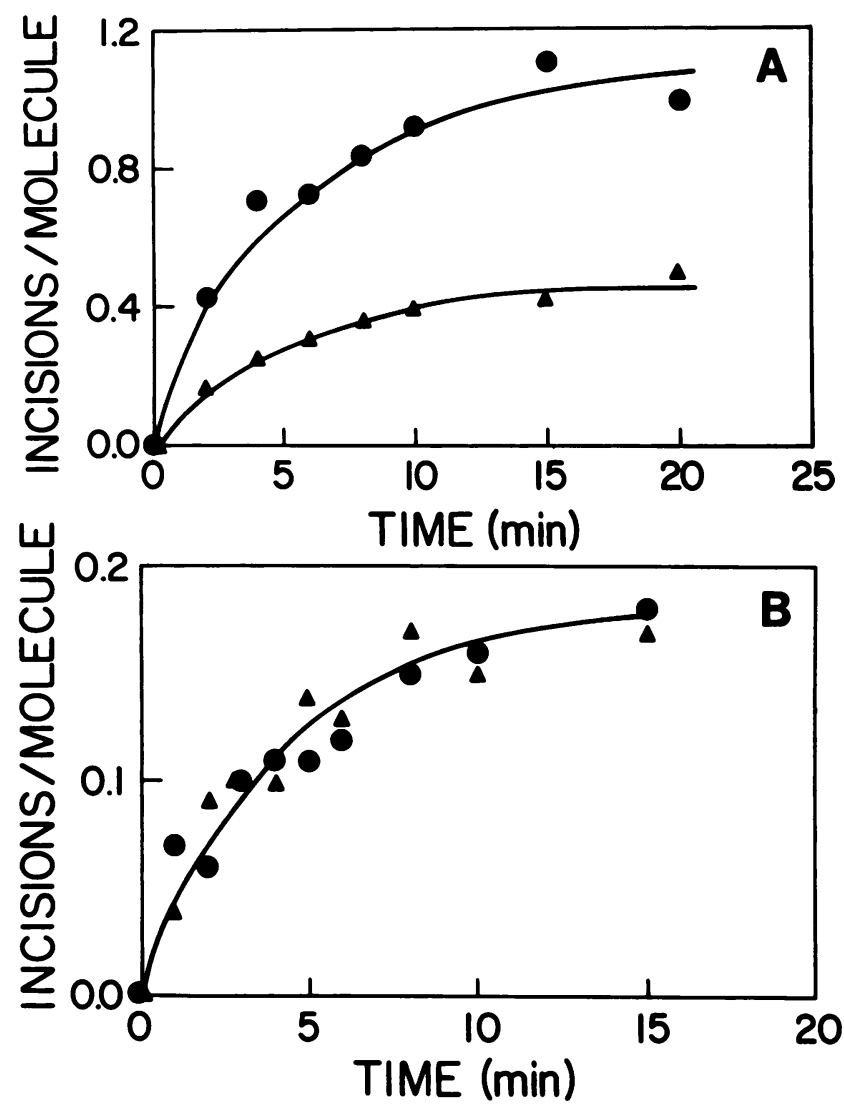

FIG. 4. Kinetics of incision of UV-irradiated or psoralen-adducted DNA by $\mathrm{ABC}$ excision nuclease in vitro in the presence or absence of yeast photolyase. Bands from gels similar to those shown in Fig. 3 were cut from the gel and dissolved, and the radioactivity was counted as described in Materials and Methods. The fraction of total counts remaining as covalently closed circular DNA at each time point was used to calculate the mean number of incisions per plasmid molecule. Because of day-to-day variation in the absolute number of incisions per molecule, the datum points shown are from a single experiment; however, as long as reactions in the presence and absence of photolyase were performed at the same time, the relative number of incisions per plasmid molecule was the same (within 10\%) in each of the three independent experiments for both types of modified DNA. (A) Results obtained with UV-irradiated DNA in the presence $(\Delta)$ or absence $(\Theta)$ of yeast photolyase; (B) results obtained with psoralen-adducted DNA in the presence $(\Delta)$ or absence $(0)$ of yeast photolyase.

deficient in dark repair and that the deficiency is closely linked to a phr mutation (3). Therefore, we propose that stimulation of excision repair by photolyase is a general phenomenon and that, in addition to playing a role in light-dependent repair, photolyase must also be considered an accessory protein in the nucleotide excision repair pathway. Whether this role extends to repair in higher mammals remains an open question, since unequivocal demonstration of enzymatic photoreactivation in these organisms has been problematic (reviewed in reference 22) and attempts to detect similar nucleotide sequences by using either the bacterial or yeast gene as a probe have been unsuccessful, perhaps because the nucleotide sequences of photolyases are not highly conserved $(22,35,52)$. Possibly in higher mammals, photolyase has lost the ability to catalyze photoreactivation but still serves its ancillary role in excision of dimers. That some DNA repair proteins have been con-

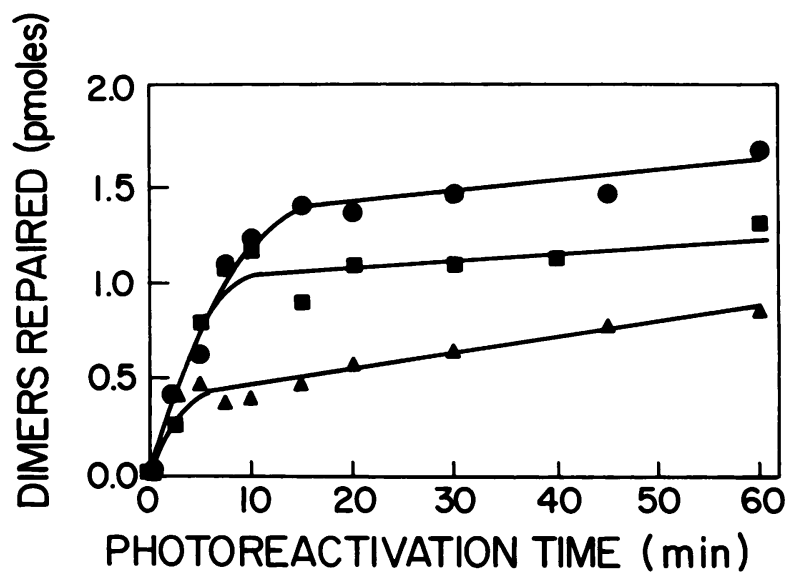

FIG. 5. Kinetics of photoreactivation by yeast photolyase in vitro in the presence or absence of the $A$ and $B$ subunits of $A B C$ excision nuclease. Photolyase was added to UV-irradiated pBR322 either with or without prior incubation of the DNA with UvrA and UvrB proteins, the mixture was exposed to photoreactivating light, and samples taken at various times during the course of the reaction were used to transform $E$. coli CSR603 to tetracycline resistance. All procedures were performed as described in Materials and Methods. Symbols: no A and B subunits present before or during photoreactivation; $\mathbf{E}, \mathrm{A}$ and $\mathrm{B}$ subunits added $10 \mathrm{~min}$ before photoreactivation at concentrations of 100 and $430 \mathrm{nM}$, respectively; $\Delta, A$ and $B$ subunits added $10 \mathrm{~min}$ before photoreactivation at concentrations of $300 \mathrm{nM}$ and $1.26 \mu \mathrm{M}$, respectively.

served, in whole or in part, from bacteria to higher mammals is supported by the detection of amino acid homology between the products of the human repair gene $E R C C 1$, the yeast $R A D 10$ gene (46), and the $E$. coli uvrC gene (5).

If the photolyases and nucleotide excision repair pathways in yeast cells and $E$. coli are similar, then why does the Phr1 photolyase stimulate excision repair in yeast cells but inhibit incision by the $E$. coli excision nuclease? Our in vitro data indicate that inhibition is attributable in whole or in part to competition between the photolyase and the A or B subunit (or both) of $\mathrm{ABC}$ excision nuclease for binding of pyrimidine dimers. The $A B C$ excision nuclease of $E$. coli cleaves the eighth phosphodiester bond $5^{\prime}$ to the dimer and the fourth or fifth phosphodiester bond $3^{\prime}$ to the dimer in the damaged strand. Comparison of these incision sites with the contacts made by $E$. coli photolyase $(1,16)$ and by the excision nuclease (47) around the dimer indicate that the enzymes must be in extremely close proximity, particularly at the $3^{\prime}$ incision site, and therefore that the tertiary structures of the enzymes are critical in determining whether stimulation or inhibition results from simultaneous binding. Although the contacts made by yeast and $E$. coli photolyases with DNA at and surrounding the dimer are quite similar (1), there are subtle differences suggesting that the yeast photolyase interacts more strongly with the complementary strand than does $E$. coli photolyase. The DNase I digestion patterns also indicate that the yeast enzyme protects a larger region $5^{\prime}$ to the dimer on both strands and, in addition, protects the region $3^{\prime}$ to the dimer more strongly than does the $E$. coli enzyme; this observation may be particularly pertinent since protection from DNase I digestion is determined both by DNA contacts and by the three-dimensional structure of the binding protein (43). The inhibition of the bacterial excision nuclease by yeast photolyase in all likelihood reflects the fact that photolyases and components of the incision complex have, of necessity, evolved in concert. 


\section{ACKNOWLEDGMENTS}

We thank Aziz Sancar for supplying the $\mathrm{ABC}$ excision nuclease and ${ }^{3} \mathrm{H}$-HMT used in these experiments.

This work was supported by Public Health Service grant GM35123 from the National Institutes of Health.

\section{LITERATURE CITED}

1. Baer, M., and G.B. Sancar. 1989. Photolyases from Saccharomyces cerevisiae and Escherichia coli recognize common binding determinants in DNA containing pyrimidine dimers. Mol. Cell. Biol. 9:4777-4788.

2. Bochner, B. R., H. Huang, G. L. Schieven, and B. N. Ames. 1980. Positive selection for loss of tetracycline resistance. J. Bacteriol. 143:926-933.

3. Boyd, J. B., and P. V. Harris. 1987. Isolation and characterization of a photorepair-deficient mutant in Drosophila melanogaster. Genetics 116:233-239.

4. Dewitt, S. K., and E. A. Adelberg. 1962. The occurrence of a genetic transposition in a strain of Escherichia coli. Genetics 47:577-585.

5. Doolittle, R. F., M. S. Johnson, I. Husain, B. Van Houten, D. C. Thomas, and A. Sancar. 1986. Domainal evolution of a prokaryotic DNA repair protein and its relationship to active-transport proteins. Nature (London) 323:451-453.

6. Ferguson, L. R., and B. S. Cox. 1974. Excision of bases accompanying the excision of dimers from DNA of UV-irradiated yeast. Mol. Gen. Genet. 135:87-90.

7. Friedberg, E. C. 1988. Deoxyribonucleic acid repair in the yeast Saccharomyces cerevisiae. Microbiol. Rev. 52:70-102.

8. Fukui, A., K. Hieda, and Y. Matsudiara. 1985. Light flash analysis of the photoenzymatic repair process in yeast cells. I. Determination of the number of photoreactivating enzyme molecules. Mutat. Res. 51:251-258.

9. Game, J. C., and B. S. Cox. 1973. Synergistic interactions between $R A D$ mutations in yeast. Mutat. Res. 20:35-44.

10. Green, G., and A. M. MacQuillan. 1980. Photorepair of ultraviolet-induced petite mutational damage in Saccharomyces cerevisiae requires the product of the PHRl gene. J. Bacteriol. 144:826-829.

11. Hall, J. D., and D. W. Mount. 1981. Mechanisms of DNA replication and mutagenesis in ultraviolet-irradiated bacteria and mammalian cells. Prog. Nucleic Acid Res. Mol. Biol. 25:53-126.

12. Harm, W., and B. Hillebrandt. 1962. A nonphotoreactivable mutant of $E$. coli B. Photochem. Photobiol. 1:271-272.

13. Hays, J. B., S. J. Martin, and K. Bhatia. 1985. Repair of nonreplicating UV-irradiated DNA; cooperative dark repair by Escherichia coli Uvr and Phr functions. J. Bacteriol. 161: 602-608.

14. Hinnen, A., J. B. Hicks, and G. R. Fink. 1978. Transformation of yeast. Proc. Natl. Acad. Sci. USA 75:1929-1933.

15. Howard-Flanders, P., and L. Theriot. 1966. Mutants of Escherichia coli $\mathrm{K}-12$ defective in DNA repair and in genetic recombination. Genetics 53:1137-1150.

16. Husain, I., G. B. Sancar, S. R. Holbrook, and A. Sancar. 1987. Mechanism of damage recognition by Escherichia coli DNA photolyase. J. Biol. Chem. 262:13188-13197.

17. Jonczyk, P., I. Fijalkowska, and Z. Ciesla. 1988. Overproduction of the $\varepsilon$ subunit of DNA polymerase III counteracts the SOS mutagenic response of Escherichia coli. Proc. Natl. Acad. Sci. USA 85:9124-9127.

18. Lawrence, C. W., and R. Christensen. 1976. UV mutagenesis in radiation sensitive strains of yeast. Genetics 82:207-232.

19. Lorence, M. C., and C. S. Rupert. 1983. Convenient construction of recA deletion derivatives of Escherichia coli. J. Bacteriol. 156:458-459.

20. MacQuillan, A. M., A. Herman, J. Coberly, and G. Green. 1981. A second photoreactivation-deficient mutation in Saccharomyces cerevisiae. Photochem. Photobiol. 34:673-677.

21. Maloy, S. R., and W. D. Nunn. 1981. Selection for loss of tetracycline resistance by Escherichia coli. J. Bacteriol. 145: $1110-1112$.

22. Meechan, P. J., K. M. Milam, and J. E. Cleaver. 1986. Evalu- ation of homology between cloned Escherichia coli and yeast DNA photolyase genes and higher eukaryotic genes. Mutat. Res. 166:143-147.

23. Miller, J. H. 1972. Experiments in molecular genetics, p. 201-205. Cold Spring Harbor Laboratory, Cold Spring Harbor, N.Y.

24. Myles, G. M., B. Van Houten, and A. Sancar. 1987. Utilization of DNA photolyase, pyrimidine dimer endonucleases, and alkali hydrolysis in the analysis of aberrant ABC excinuclease incisions adjacent to UV-induced DNA photoproducts. Nucleic Acids Res. 15:1227-1244.

25. Prakash, L. 1981. Characterization of postreplication repair in Saccharomyces cerevisiae and effects of rad16, rad18, rev3, and rad52 mutations. Mol. Gen. Genet. 184:471-478.

26. Resnick, M. A. 1968. Genetic control of lethality and mutagenesis in Saccharomyces cerevisiae, U.S. Atomic Energy Commission Document no. UCLRL 18404, p. 57. U.S. Atomic Energy Commission, Washington, D.C.

27. Resnick, M. A. 1969. A photoreactivationless mutant of Saccharomyces cerevisiae. Photochem. Photobiol. 9:307-312.

28. Rupert, C. S. 1962. Photoenzymatic repair of ultraviolet damage in DNA. II. Formation of the enzyme-substrate complex. J. Gen. Physiol. 45:725-741.

29. Rupp, W. D., and P. Howard-Flanders. 1968. Discontinuities in the DNA synthesized in a defective strain of Escherichia coli following ultraviolet irradiation. J. Mol. Biol. 31:291-304.

30. Rupp, W. D., C. E. Wilde III, D. L. Reno, and P. HowardFlanders. 1971. Exchanges between DNA strands in ultraviolet irradiated Escherichia coli. J. Mol. Biol. 61:25-44.

31. Sancar, A., K. A. Franklin, and G. B. Sancar. 1984. Escherichia coli DNA photolyase stimulates UvrABC excision nuclease in vitro. Proc. Natl. Acad. Sci. USA 81:7397-7401.

32. Sancar, A., A. M. Hack, and W. D. Rupp. 1979. A simple method for the identification of plasmid-coded proteins. J. Bacteriol. 137:692-693.

33. Sancar, A., and C. S. Rupert. 1978. Determination of plasmid molecular weights from ultraviolet sensitivities. Nature (London) 272:471-472.

34. Sancar, A., and G. B. Sancar. 1988. DNA repair enzymes. Annu. Rev. Biochem. 57:29-67.

35. Sancar, G. B. 1985 . Sequence of the Saccharomyces cerevisiae PHRI gene and homology of the Phrl photolyase to E. coli photolyase. Nucleic Acids Res. 13:8231-8246.

36. Sancar, G. B. 1985. Expression of a Saccharomyces cerevisiae photolyase gene in Escherichia coli. J. Bacteriol. 161:769-771.

37. Sancar, G. B., and F. W. Smith. 1988. Construction of plasmids which lead to the overproduction of yeast $P H R 1$ photolyase in Saccharomyces cerevisiae and Escherichia coli. Gene 64:87-98.

38. Sancar, G. B., F. W. Smith, and P. F. Heelis. 1987. Purification of the yeast PHRI photolyase from an Escherichia coli overproducing strain and characterization of the intrinsic chromophores of the enzyme. J. Biol. Chem. 262:15457-15465.

39. Sancar, G. B., F. W. Smith, M. C. Lorence, C. S. Rupert, and A. Sancar. 1984. Sequences of the $E$. coli photolyase gene and protein. J. Biol. Chem. 259:6033-6038.

40. Sancar, G. B., F. W. Smith, and A. Sancar. 1983. Identification and amplification of the $E$. coli phr gene product. Nucleic Acids Res. 11:6667-6678.

41. Sancar, G. B., F. W. Smith, and A. Sancar. 1985. Binding of Escherichia coli DNA photolyase to UV-irradiated DNA. Biochemistry 24:1849-1855.

42. Sherman, F., G. L. Fink, and C. W. Lawrence. 1978. Methods in yeast genetics. Cold Spring Harbor Laboratory, Cold Spring Harbor, N.Y.

43. Suck, D., and C. Oefner. 1986. Structure of DNase I at $2.0 \AA$ resolution suggests a mechanism for binding to and cutting DNA. Nature (London) 321:620-625.

44. Thomas, D. C., M. Levy, and A. Sancar. 1985. Amplification and purification of UvrA, UvrB, and UvrC proteins of Escherichia coli. J. Biol. Chem. 260:9875-9883.

45. Unrau, P., R. Wheatcroft, and B. S. Cob. 1971. The excision of pyrimidine dimers from DNA of ultraviolet irradiated yeast. Mol. Gen. Genet. 354:359-362. 
46. van Duin, M., J. de Witt, H. Odijk, A. Westerveld, A. Yasui, M. H. M. Koken, J. H. Hoeijmakers, and D. Bootsma. 1986. Molecular characterization of the human excision repair gene ERCC-1: cDNA cloning and amino acid homology with the yeast DNA repair gene $R A D 10$ Cell 44:913-923.

47. Van Houten, B., H. Gamper, A. Sancar, and J. E. Hearst. 1987. DNase I footprint of ABC excinuclease. J. Biol. Chem. 262: 13180-13187.

48. Walker, G. C. 1984. Mutagenesis and inducible responses to deoxyribonucleic acid damage in Escherichia coli. Microbiol. Rev. 48:60-93.

49. Wilcox, D. R., and L. Prakash. 1981. Incision and postincision steps of pyrimidine dimer removal in excision-defective mutants of Saccharomyces cerevisiae. J. Bacteriol. 148:618-623.
50. Yamamoto, K., Y. Fujiwara, and H. Shinagawa. 1983. Evidence that the phr+ gene enhances the ultraviolet resistance of Escherichia coli recA strains in the dark. Mol. Gen. Genet. 192: 282-284.

51. Yamamoto, K., Y. Fujiwara, and H. Shinagawa. 1984. A multicopy phr-plasmid increases the ultraviolet resistance of a recA strain of Escherichia coli. Mutat. Res. 131:11-18.

52. Yasui, A., and S. A. Langeveld. 1985. Homology between the photoreactivation genes of Saccharomyces cerevisiae and Escherichia coli. Gene 36:349-355.

53. Yasui, A., and W. Laskowski. 1975. Determination of the number of photoreactivating enzyme molecules per haploid Saccharomyces cerevisiae cell. Int. J. Radiat. Biol. 28:511-518. 